\title{
O CAMPONÊS E A FOTOGRAFIA ${ }^{1}$
}

\author{
Pierre Bourdieu
}

\author{
Marie-Claire Bourdieu
}

RESUMO

Recorrendo a uma etnografia da aldeia do Sudoeste francês onde o autor passou sua infância, este artigo analisa os usos sociais e o sentido das fotografias e da prática fotográfica na sociedade camponesa do Béarn nos inícios de 1960. A fotografia surgiu ali, pela primeira vez, durante as grandes cerimônias da vida familiar e coletiva, como os casamentos, em que preenchia a função de afirmar a unidade, posição e fronteiras das linhagens envolvidas. Tais cerimônias podiam ser fotografadas porque estavam fora da rotina diária, e deviam ser fotografadas para solenizar e materializar a imagem que o grupo pretendia apresentar de si próprio. Por isso, as fotografias são vistas e apreciadas não em si mesmas e por si mesmas, isto é, em termos das suas qualidades técnicas ou estéticas, mas como sociogramas leigos que possibilitam um registro visual das relações e papéis sociais existentes.

PALAVRAS-CHAVE: fotografia; campesinato; tecnologia; parentesco; estética; cultura local; Béarn.

\begin{abstract}
A fotografia é um objeto que me interessou. Considerei, naturalmente, o fato desta ser a única prática com uma dimensão artística acessível a todos e de ser o único bem cultural universalmente consumido. Achei, assim, que, por meio desse desvio, conseguiria desenvolver uma teoria geral da estética. Era algo, ao mesmo tempo, muito modesto e muito ambicioso. É corrente dizer que as fotografias populares são horriveis etc. Eu queria, em primeiro lugar, entender por que razão isso é assim e, em segundo, tentar explicar, por exemplo, a frontalidade dessas imagens e o fato de nelas revelarem-se relações entre pessoas e uma série de coisas que indicam a medida de sua necessidade e que, por isso, têm o efeito de reabilitá-las. E então decidi analisar uma coleção de fotografias que pertenciam a Jeannot, um amigo de infância: examinei-as uma a uma e embrenhei-me nelas. Parece que encontrei muita coisa nesta caixa de sapatos.
\end{abstract}

Pierre Bourdieu

\section{INTRODUÇÃO}

O que explica que a fotografia e, mais precisamente, a prática fotográfica ocupe um lugar tão

\footnotetext{
$1 \mathrm{O}$ presente artigo é uma tradução de The peasant and photography (BOURDIEU \& BOURDIEU, 2004). A versão e a adaptação para o inglês ficaram a cargo de Loïc Wacquant e Richard Nice. A tradução portuguesa do texto publicado na Ethnography não deixou de recorrer, sempre que surgiram dúvidas, à versão francesa (BOURDIEU \& BOURDIEU, 1965). Tradução para o português de Helena Pinto e José Madureira Pinto. Revisão e adaptação para o português falado no Brasil: Fábia Berlatto e Bruna Gisi. Revisão técnica da tradução: Adriano Codato, Renato Perissinotto e José Szwako. Os títulos das seções são da edição de Ethnography. A versão brasileira é diferente da versão portuguesa.
}

limitado entre os camponeses ${ }^{2}$ ? Terá isso a ver com ignorância, ligada a falta de informação sobre as tecnologias modernas, ou com uma vontade de as ignorar, isto é, com uma escolha cultural genuína que deve ser entendida tendo em conta os valores próprios da sociedade camponesa? Se esta última hipótese for sustentável, não poderia a história de uma tecnologia, que contradiz estes valores naquilo que lhes é mais essencial, revelar o núcleo principal da ética camponesa?

2 Este artigo apresenta uma primeira versão das informações e dos documentos também usados, em parte, num livro publicado simultaneamente, Un art moyen. Essais sur les usages sociaux de la photographie (BOURDIEU, 1965b). 
Devido à dualidade da sua estrutura, a aldeia de Lesquire, no Béarn ${ }^{3}$, propiciava uma autêntica situação experimental, permitindo tanto estudar a difusão de uma tecnologia moderna em um meio social camponês, quanto analisar as prováveis relações entre "citadinização" [citadinization], a indução de hábitos urbanos, e o aparecimento e o aumento da prática fotográfica.

A oposição entre a vila (bourg) (com 264 habitantes em 1954) e os hameaux circundantes (agrupamentos dispersos de fazendas, somando 1090 habitantes) é muito marcada em termos de ecologia e morfologia (a dimensão das famílias nas pequenas aldeias é muito superior) e domina todos os aspectos da vida local. Em primeiro lugar, organiza a vida econômica, já que o bourg foi monopolizando gradualmente todas as funções urbanas desde 1918: é o lugar onde moram aposentados, funcionários civis e profissionais liberais (que no conjunto formam $44,2 \%$ dos chefes de família), artesãos e comerciantes $(36,6 \%)$; os trabalhadores agrícolas, operários e proprietários das terras não são mais do que uma pequena minoria da população ( $11,5 \%$ ), ao mesmo tempo que constituem a quase totalidade da população $(88,8 \%)$ das pequenas aldeias. Entre as últimas casas do bourg, onde se fala francês, e as primeiras propriedades agrícolas, a menos de cem metros de distância, onde as pessoas falam béarnais, uma língua que os habitantes da vila consideram inferior e vulgar, passa uma verdadeira fronteira: a que separa esses mesmos habitantes com pretensões urbanas dos camponeses das aldeias, agarrados ou acorrentados às suas tradições e, por isso, frequentemente julgados como retrógrados ${ }^{4}$.

\section{RELAÇÕES SOLENIZADAS: A FOTOGRA- FIA COMO SOCIOGRAMA}

As imagens fotográficas entraram cedo na sociedade camponesa, muito antes da prática de tirar fotografias. Foram introduzidas pelas pesso-

\footnotetext{
${ }^{3}$ Lesquire é o pseudônimo da aldeia isolada nesta região montanhosa do sudoeste francês, perto da fronteira da Espanha, onde Pierre Bourdieu passou a sua infância. É o local onde ele realizou o trabalho de campo sobre as relações de gênero e de parentesco entre os camponeses, em 1959-1961 e nos anos seguintes, em paralelo com um trabalho semelhante entre os cabilas, na Argélia [Nota de Loïc Wacquant e Richard Nice].

4 Para uma análise mais aprofundada sobre essa oposição, cf. BOURDIEU, 1962; BOURDIEU, 2002.
}

as do bourg, em tudo predispostas a assumir o papel de intermediários entre os camponeses das aldeias e a cidade. $\mathrm{O}$ seu uso tornou-se rapidamente obrigatório, especialmente em casamentos, uma vez que vieram preencher funções pré-existentes à sua introdução. De fato, a fotografia surge, desde o início, como o acompanhamento necessário das grandes cerimônias da vida familiar e coletiva. Se se aceitar, com Durkheim (1995), que as cerimônias têm por função reanimar o grupo, percebe-se por que a fotografia deve estar associada a elas, já que provê os meios para eternizar e solenizar estes momentos intensos da vida social, em que o grupo reafirma a sua unidade. No caso dos casamentos, por exemplo, a imagem que fixa para sempre o grupo reunido, ou melhor, a reunião de dois grupos, inscreve-se de forma necessária num ritual cuja função é a de consagrar, ou seja, sancionar e santificar a união entre dois grupos através da união de dois indivíduos. Não é por acaso que a ordem em que a fotografia foi introduzida no ritual das cerimônias corresponde à importância social de cada uma delas. A mais antiga e a mais tradicional fotografia, como explica J.-P. A. (nascido em Lesquire em 1885), é a fotografia de casamento ${ }^{5}$ :

A primeira vez que fui num casamento onde foram tiradas fotografias em frente da igreja deve ter sido em 1903. Era o casamento de alguém do campo que tinha parentes na cidade, esse tipo de coisa. $\mathrm{O}$ fotógrafo mandou que as pessoas se colocassem nos degraus da igreja, e alguns estavam sentados e outros estavam de pé atrás deles. Tinha montado tudo, com bancos, com tapetes para ninguém se sujar. Ainda não havia carros naquele tempo, mas ele [o fotógrafo] tinha vindo de carro. As pessoas falavam muito disso. O noivo era um 'americano' [um emigrante local na América], L., da família Ju., uma grande família, que casou com a herdeira da família R. Foi um grande casamento, ele vinha da América. Andava com um pequeno rabo-de-cavalo, uma corrente de ouro no colete. Essa foi a primeira ocasião de que me lembro, talvez tenham tido outras antes, mas essa foi impressionante! Os camponeses mais antigos nunca tinham visto uma coisa daquele tipo [...]. Mais tarde os fotógrafos apareciam por conta própria quando sabiam que um casamento estava

5 J.-P. A., de 85 anos, viúvo, com escolaridade até o primário, vivia no bourg no período desta pesquisa, mas tinha passado toda a sua juventude num hameau. Nas entrevistas com ele alternava-se entre o francês e $\mathrm{o}$ béarnais. 
para acontecer [...]. Eram eles que se apresentavam, as famílias não precisavam perguntar nada. Hoje em dia são as pessoas que os chamam. Mas isso deu, de fato, um grande salto com o fim da Guerra Mundial, em 1919. O hábito de ir a Pau tirar uma fotografia vem também deste tempo [...]. Era o fotógrafo que aparecia, oferecia os seus serviços. Senão, talvez eles nunca o chamariam. Mas, uma vez que ele estava lá, não se atreviam a dizer que não. Nada era muito caro naquele tempo.

A fotografia de casamento só se impôs tão rapidamente porque encontrou as suas condições sociais de existência: os gastos e o desperdício são parte dos comportamentos festivos, particularmente as despesas ostentatórias que ninguém podia evitar sem ver diminuída a sua honra.

No começo, o fotógrafo andava com as fotografias, para ver quem as queria. Recolhia os nomes e mais tarde as enviava. Tinha que pagar adiantado. Oh! Não era assim, tão caro. Dois francos por pessoa. E ninguém ousava recusar. E então ficavam contentes ao vê-las em casa depois do casamento. $\mathrm{O}$ cavalheiro pagava a fotografia para a dama. Era o que devia ser feito num dia como aquele" (J.-P. A.). "A fotografia de grupo era obrigatória. Alguém que não a comprasse era visto como um miserável (picheprim). Isso era considerado um insulto para aqueles que os tinham convidado. Significaria falta de consideração. À mesa, à vista de todos, é impossível dizer não (J. B.).

Comprar as fotografias é um tributo prestado àqueles que fizeram o convite. A fotografia é objeto de trocas reguladas; pertence ao circuito dos dons e contra-dons obrigatórios a que os casamentos e outras cerimônias dão lugar. Sendo um celebrador, cuja presença confirma a solenidade do ritual, o fotógrafo oficial pode ser secundado pelo fotógrafo amador, mas nunca poderá ser substituído por esse último ${ }^{6}$.

É só por volta de 1930 que fotografias da primeira comunhão começam a surgir, enquanto que as fotografias de batizados são ainda mais recentes e raras. Durante os últimos anos, alguns camponeses tiraram proveito da presença dos fotógrafos em feiras agrícolas para tirarem uma fotografia com o gado, embora sejam raros esses ca-

\footnotetext{
6 A fotografia marca a transição do ritual religioso para o ritual secular: a festa de casamento. Ela é tirada nos degraus da igreja.
}

sos. Nos batizados, que nunca deram lugar a grandes cerimônias, e onde estavam presentes apenas os parentes mais próximos, a fotografia permanece excepcional. Mas a primeira comunhão dá a muitas mães a oportunidade de ter uma fotografia dos seus filhos 7 : só se pode aplaudir uma mãe que age assim, e tanto mais quanto maior for a importância da criança na sociedade. $\mathrm{Na}$ antiga sociedade camponesa, uma criança nunca era o centro das atenções, como acontece hoje em dia. As grandes festas e cerimônias da aldeia eram sobretudo eventos para os adultos, e foi apenas a partir de 1945 que as celebrações destinadas às crianças (por exemplo, o Natal e a Primeira Comunhão) se tornaram importantes. À medida que a sociedade dedica mais atenção às crianças e, dessa forma, às mulheres enquanto mães, o hábito de tirar fotografias de crianças aumenta. Num álbum de fotografias de um pequeno proprietário das aldeias (B. M.), os retratos de crianças tiradas depois de 1945 somavam mais da metade, enquanto que nos anos anteriores a 1939 não há quase nenhuma (três, para ser mais preciso). Nessa época, fotografava-se sobretudo os adultos. Em segundo lugar, grupos familiares, pais e filhos juntos, e só excepcionalmente crianças sozinhas. Agora, acontece exatamente o contrário. Mas fotografar crianças é em si mesmo aceito, em grande medida, por ter uma função social. A divisão do trabalho entre sexos atribui à mulher a tarefa de manter relações sociais com os membros do grupo que se encontram longe, começando pela sua própria família. Assim como as cartas, e bem melhor do que elas, as fotografias assumem um importante papel na atualização contínua do reconhecimento mútuo ${ }^{8}$. É costume levar as crianças para visitar os parentes (pelo menos uma vez e, se for possível, periodicamente) que vivem fora da aldeia e, em primeiro lugar, a mãe da esposa, quando esta vem de fora. É a mulher que toma a iniciativa destas viagens, e que as faz, por vezes, sem a presença do marido. Enviar uma fotografia tem a mesma função: através da imagem, apre-

7 Tal como nas festas de casamento, a fotografia insere-se no circuito das trocas ritualmente impostas. É acrescentada à imagem-recordação que a criança traz aos parentes $\mathrm{e}$ vizinhos em troca de um presente.

8 O envio das fotografias após o casamento provoca, geralmente, um ressurgimento da correspondência: "Os 'exilados' pedem para que os casais que aparecem na foto sejam identificados, particularmente os jovens de quem apenas conhecem os pais" (A. B.). 
senta-se o novo descendente a todo o grupo que deve "reconhecê-lo".

Nessa perspectiva, é compreensível que as fotografias devam ser objeto de uma leitura sociológica; e que nunca sejam consideradas em si mesmas e por si mesmas em termos das suas qualidades técnicas e estéticas. Parte-se do princípio de que o fotógrafo sabe fazer o seu trabalho e não se tem qualquer base para fazer comparações. A fotografia deve apenas possibilitar uma representação suficientemente crível e precisa para permitir o reconhecimento. É metodicamente inspecionada e observada, à distância, de acordo com a lógica que governa o conhecimento dos outros no quotidiano. Através do confronto de conhecimentos e experiências, situa-se cada pessoa por referência à linhagem a que pertence e, frequentemente, a leitura de fotografias antigas assume a forma de uma conferência sobre ciência genealógica, quando a mãe, a especialista no assunto, ensina à criança as relações que a unem a cada uma das pessoas na imagem. Mas, acima de tudo, averigua-se quem participou da cerimônia; como eram constituídos os casais; o campo de relações sociais de cada família é analisado; repara-se em quem falta, indicador de discórdias, e as presenças que conferem honra. Para cada convidado, a fotografia é uma espécie de troféu, um sinal e uma fonte de importância social ("tem-se orgulho em poder mostrar que se esteve no casamento", diz J. L.). Para as famílias dos recémcasados, e para o próprio casal, a foto testemunha a posição hierárquica da família, ao relembrar o número e a qualidade dos convidados. Os convidados de B. M., filho de uma "pequena família" da aldeia, são sobretudo parentes e vizinhos, predominando o princípio da seleção tradicional. Já na fotografia de casamento de J. B., um habitante da vila, com posses, pode-se ver, ao lado dos convidados ilustres, os amigos do trabalho e da escola do noivo, e até mesmo os da noiva. Em suma, a fotografia de casamento é um verdadeiro sociograma, e é visto como tal.

Fotografar grandes cerimônias é possível porque $-\mathrm{e}$ apenas porque - essas imagens captam comportamentos que são socialmente aceitos e socialmente regulados, ou seja, já solenizados. Nada além do que deve ser fotografado pode ser fotografado ${ }^{9}$. A cerimônia pode ser fotografada

9 "Não, o fotógrafo nunca tira fotografias do baile. Isso porque está situada fora daquilo que é a rotina diária, e deve ser fotografada porque materializa a imagem que o grupo, qua grupo, pretende apresentar de si próprio. O que é fotografado, e apreendido pelo leitor da fotografia, não são propriamente indivíduos na sua particularidade singular, mas sim papéis sociais - o marido, o rapaz na primeira comunhão, o militar - ou relações sociais - o tio da América ou a tia de Sauvagnon. Por exemplo, a coleção de B. M. inclui uma fotografia que ilustra, de forma perfeita, o primeiro tipo. É a imagem do cunhado do pai vestido como carteiro da cidade: com o boné de pala na cabeça, uma camisa branca de gola alta, uma gravata com quadrados brancos, uma sobrecasaca de corte arredondado, sem lapelas, ao peito o distintivo com o número 471, um colete alto adornado com botões dourados e uma corrente de relógio pendurada. Ele posa de pé, com a mão direita repousada numa mesinha de estilo oriental. O que a filha emigrante enviou para a família não foi a imagem do seu marido, mas o símbolo do seu sucesso social ${ }^{10}$. O segundo tipo é ilustrado por uma fotografia tirada no período de uma estadia do cunhado de $\mathrm{B}$. M. em Lesquire. Ela soleniza o encontro das duas famílias juntando tios e sobrinhas, tias e sobrinhos. Como se a intenção fosse a de manifestar que o verdadeiro objeto da fotografia não são os indivíduos, mas as relações entre eles. Os pais de uma família seguram nos braços os filhos da outra família ${ }^{11}$.

não tem valor aos olhos das pessoas. Nunca vi nenhuma" (J. L.).

10 De maneira análoga, entre as fotografias expostas nas casas, vê-se freqüentemente a foto anual da equipe de rúgbi, alinhada numa pose formal; e só muito raramente fotografias representando fases do jogo, que são relegadas para a "caixa das fotografias".

11 A maioria das fotografias recentes no álbum de B. M. foram tiradas por amadores. Algumas das fotografias da esposa e da filha de B. M. foram tiradas durante as visitas à cunhada (que vive em Oloron, uma pequena cidade a 80 quilômetros de distância), no mercado ou na feira. As crianças estão alinhadas à frente, e os adultos atrás delas. Estas outras fotos amadoras, como a agora descrita, foram tiradas durante a visita do cunhado, que mora em Paris. À primeira vista, há quatro delas que se distinguem: aquelas que mostram B. M. em frente ao gado, com o aguilhão ao ombro, e o sobrinho com a mesma postura. Serão, de fato, instantâneos da vida quotidiana? Na realidade, elas são encenadas e alegóricas: por um lado, o pequeno parisiense, fingindo ser um camponês; por outro, não B. M. como uma pessoa singular, mas como uma fotografia-postal do Béarn, 
Na maioria das casas camponesas, as fotografias são mantidas "fechadas" numa caixa, com exceção da fotografia do casamento e de certos retratos. Seria indecente, ou ostentatório, mostrar imagens de membros da família a qualquer um que pudesse aparecer. As fotos das cerimônias são demasiado solenes ou íntimas para serem exibidas no espaço da vida quotidiana ${ }^{12}$; o local próprio para elas é ou o compartimento nobre, a sala de estar, ou, para as mais íntimas, como as fotografias de parentes falecidos, o quarto, junto às imagens religiosas, como o crucifixo e o ramo benzido. As fotografias amadoras são guardadas em gavetas. De maneira oposta, em casas da pequena burguesia da aldeia elas adquirem um valor decorativo ou afetivo: ampliadas e enquadradas, decoram as paredes da sala de estar, juntamente com as recordações de viagens. Chegam mesmo a invadir o altar até então apropriado aos valores de família, a chaminé do fogão da sala, tirando o lugar das medalhas, prêmios e diplomas da escola primária que antigamente costumavam ali estar expostos, mas que a jovem esposa da aldeia relegou, discretamente, considerando-os um pouco ridículos, para o canto mais obscuro, atrás da porta, de modo a não chocar os "mais velhos".

\section{UMA INOVAÇÃO SUSPEITA: A PRÁTICA FOTOGRÁFICA E O ETHOS DOS CAMPO- NESES}

Enquanto as imagens fotográficas, e especialmente as fotografias de casamentos, foram adotadas pela comunidade inteira desde o início, sem qualquer resistência, como um momento obrigatório do ritual social, a prática fotográfica foi inicialmente restringida a alguns fotógrafos amadores isolados, todos pertencentes à burguesia da aldeia.

No meu tempo, só os fidalgos das aldeias e alguns emplegats ('empregados', isto é, trabalhadores de colarinho branco e profissionais liberais) tiravam fotos: os cobradores, os inspetores, os professores e o doutor Co (J.-P. A.).

representando um camponês à frente do gado, com o corpo direito, a boina inclinada por cima da orelha, o aguilhão ao ombro.

12 O grande cômodo comum, ou seja, a cozinha, possui somente uma decoração impessoal, igual em todo lugar: o calendário dos correios ou dos bombeiros, postais comprados em Pau (a cidade mais próxima, a doze quilômetros de distância) ou trazidos de uma ida a Lourdes.
Mesmo hoje, enquanto entre os camponeses das aldeias é freqüente haver apenas um homem, ainda jovem e solteiro, que tira fotografias, na vila existe um pequeno número de amadores que as tira de forma mais ou menos regular. Dependendo fortemente da renda, a prática da fotografia está manifestamente ligada ao local de residência, pela mediação do grau com que se aspira ou se adere aos valores urbanos. De fato, nada seria mais errado do que tentar explicar a raridade da prática fotográfica, na sociedade camponesa, através de simples determinismos negativos. Nem as barreiras econômicas, tais como o elevado custo do equipamento, nem as barreiras tecnológicas, e nem mesmo o baixo nível de informação podem explicar esse fenômeno. Os camponeses usam a fotografia, e podem usá-la, estritamente como consumidores; e usam, pois, de forma seletiva porque o sistema de valores que partilham, cujo ponto central é uma determinada imagem do camponês perfeito, os impede de se tornarem produtores.

Se a fotografia é vista como um luxo, é primeiramente porque o ethos camponês exige que os gastos dedicados ao aumento do patrimônio, ou da modernização do equipamento agrícola, tenham prioridade sobre os gastos com o consumo. De uma forma geral, qualquer despesa que não seja sancionada pela tradição é considerada um desperdício. Mas isso não é tudo: a inovação é sempre suspeita aos olhos do grupo, e não só em si mesma, isto é, enquanto negação da tradição. As pessoas estão acostumadas a ver nela uma forma de se distingüir, de se sobressair, de fascinar ou de desmerecer os outros. E isso é uma afronta ao princípio que domina toda a existência social, e que nada tem a ver com igualitarismo. De fato, a ironia, a gozação e a fofoca têm como função trazer de volta à ordem, isto é, à conformidade e à uniformidade, alguém que, pelo seu comportamento inovador, parece querer dar uma lição ou desafiar toda a comunidade. Seja esta ou não a sua intenção, não há como escapar à suspeita. Ao invocar experiências passadas e chamar os outros para testemunharem, pretende-se negar que a inovação corresponda a uma necessidade real. Daí, ela só pode ser ostentatória.

Mas a desaprovação coletiva varia de acordo com a natureza da inovação e da área em que é introduzida. Quando diz respeito às técnicas agrícolas e formas de colheita, nunca provoca a total e brutal condenação porque, apesar de tudo, é dado o benefício da dúvida ao inovador: é que, não 
obstante as aparências, o seu comportamento pode estar repleto dos mais louváveis motivos, isto é, a vontade de aumentar o valor do patrimônio. Nesses casos, ele trai a tradição camponesa mas permanece um camponês. Além disso, a condenação moral pode adotar uma aparência de ceticismo do técnico e do homem experiente: a sanção da iniciativa [técnica] dependerá dos resultados. De qualquer forma, como corre o risco de falhar ou de se sujeitar ao ridículo, o inovador inspira respeito.

Pelo contrário, a comunidade vive inovações que suspeita serem desprovidas de qualquer justificação racional ou razoável como um desafio e uma desaprovação. Isso acontece porque, à maneira de um dom que exclui um contra-dom, o comportamento ostentatório, ou o comportamento percebido enquanto tal, coloca o grupo numa situação de inferioridade, e só pode ser entendido como uma afronta, em que todos se sentem atingidos na sua auto-estima. Nesse caso, a reprovação e a repressão são imediatas e impiedosas. "Com quem é que ele pensa que está brincando? Quem é que ele pensa que é?" Como sinal de status, a prática fotográfica não pode senão exprimir um esforço para alguém se elevar socialmente. Essa vontade de distinção é contrariada pela lembrança das raízes comuns: "Nós sabemos de onde ele veio". "O pai dele usava tamancos!"13.

Considerado um luxo fútil, a prática fotográfica seria considerada para um camponês uma barbaridade; entregar-se a tal fantasia seria mais ou menos como um homem dar um passeio com a mulher numa noite de verão, como fazem os aposentados da vila:

Isso é bom para os que estão de férias. Isso são coisas da cidade. Um camponês que andasse com uma máquina dependurada no ombro não seria mais que um cavalheiro fracassado (u moussu manquat). É necessário mãos delicadas para mexer naquelas coisas. E o dinheiro então? É caro. Toda aquela parafernália custa uma fortuna! (F. M.).

13 "Ele quer tirar fotografias! Está se tornando um verdadeiro senhor (s'en-monsieure), não está? Daqui a pouco vai estar tirando fotografias dos porcos e do chiqueiro". "Seria melhor se trocasse o arado e aquele miserável par de vacas que tem para lavrar!" "Um aparelho daqueles, e com aquele terno horrível!"
Associada à vida urbana, a prática da fotografia é vista como uma manifestação do desejo de parecer urbano, de se armar como um cavalheiro (moussureya). E então é vista como uma traição de novo-rico. "S'en-monsieurer" (literalmente, "encavalheirar-se", en-moussuri's em Béarnais) é uma dupla ofensa aos imperativos fundamentais da ética camponesa. Na verdade, isso significa sobressair-se renegando a sua existência como membro do grupo e como camponês ${ }^{14}$. Ao verdadeiro morador da cidade, totalmente estranho ao grupo, admite-se que tire fotografias porque isso faz parte da imagem estereotipada que o camponês tem dele. A máquina fotográfica é um dos atributos distintivos do veranista ("vacancier" lou bacancié). Os camponeses aceitam suas fantasias, com uma certa ironia, e fazem a pose esperada, diante da junta de bois, pensando: "Esta gente tem tempo para desperdiçar, e dinheiro para esbanjar". Há muito menos tolerância com os nativos da aldeia que regressam da cidade, e menos ainda com os habitantes da vila que são suspeitos de tirarem fotografia para se parecerem com gente da cidade. Em outras palavras: não é a prática fotográfica em si que é recusada. Como um capricho e uma futilidade de gente da cidade, ela convém perfeitamente aos "outsiders" - mas só a eles. Nesse aspecto, o comportamento inovador dos habitantes da cidade não pode inspirar imitação [por parte do camponês] porque a tolerância de que goza não é mais que a expressão da vontade de ignorá-lo, ou da recusa em identificar-se com ele ${ }^{15}$.

No entanto, assim como varia de acordo com a natureza da inovação, a reprovação também varia segundo a posição social e o status do inova-

\footnotetext{
14 Isso explica a atitude ambígua do camponês em relação ao funcionário do bourg. Por um lado, como representante da administração central e depositário da autoridade governamental, suscita respeito e consideração. Mas, por outro lado, o homem do bourg é, de fato, o burguês, alguém que abandonou a terra e rompeu ou renegou os laços que o prendiam ao seu ambiente social original.

15 A maioria dos camponeses entrevistados mencionaram parentes que adotaram a fotografia desde que deixaram a aldeia. Mas um camponês que vê a irmã ou o primo, o filho ou o irmão, que saiu para ir trabalhar na indústria, regressar com uma máquina, é levado a associar a fotografia à adoção de modos de vida urbanos. Assim sendo, esses exemplos, em vez de o seduzirem, mesmo quando dizem respeito a parentes próximos, apenas vêm confirmar a convicção de que a fotografia "não é para nós".
} 
dor. A lógica da seleção que preside os empréstimos e, da mesma forma, os valores que comandam esta seleção, podem ser apreendidos não apenas nas defesas que o ethos camponês opõe a tudo aquilo que o ameaça, mas também, e sobretudo, nas exceções que admite. Se a fotografia pode ser permitida às mulheres, ou melhor, às mães de família, é porque serve a propósitos socialmente aceitos; e se, como atividade fútil, é tolerada na adolescência, o período fútil da vida, estas são transações e compromissos com a regra que provêm dos próprios valores de que a regra participa. Assim, os adolescentes sempre tiveram um direito estatutário à frivolidade lícita, ou seja, simbólica e onírica; o mesmo é verdade, então, para a fotografia como para a dança e, de uma forma mais geral, para todas as técnicas de cortejo e de festejar: "Eles tiram fotografias quando estão apaixonados (cuan s'amourouseyen), nos dias de baile".

No campo, assim que um casal se casa, há outras coisas em que pensar. Be., o camponês mais rico, tirou fotografias do seu noivado e, posteriormente, do casamento. Agora vivem sem dinheiro (ils tirent la guignorre), pior do que pequenos proprietários como nós. Pequenos caprichos como esses são rapidamente esquecidos quando as necessidades da família surgem, como acontece, aliás, com o gosto por dançar. E, na minha opinião, isso é normal. E depois, quanto a fotografias, os profissionais estão lá para isso, pelo menos nas grandes ocasiões (R. M., de Debat, uma aldeia no vale Gave, a 10 quilômetros de Lacq).

Estas práticas, aceitáveis para os mais novos, são de qualquer forma abandonadas a partir do momento do casamento, que marca uma acentuada ruptura na existência. De um dia para o outro, acabaram-se os bailes da aldeia ou as saídas e, por conseguinte, a fotografia que muitas vezes lhes estava associada. "Parei logo depois da minha lua-de-mel”, diz J. B. "[...] Agora tenho muitas outras coisas com que me preocupar". E a mulher intervém: "Oh!, de fato, agora ele tem outras coisas com que se preocupar". Esse homem, que antigamente relatava com orgulho as suas férias em Biarritz, ou as visitas a Paris; que afirma não ter o prazer de tirar fotografias, embora gaste muito do seu tempo na caça ao pombo selvagem, fala agora apenas de trabalho, a única atividade digna de um adulto responsável.

\section{POSTURA FOTOGRÁFICA E SENTIMEN- TO DE HONRA}

Até a postura que o camponês adota em frente à máquina parece expressar os valores camponeses e, mais precisamente, o sistema de modelos que governa as relações com os outros na sociedade camponesa. Os indivíduos apresentam-se, geralmente, de frente, no centro da fotografia, de pé e em corpo inteiro, o que quer dizer que ficam colocados a uma distância respeitável. Em fotografias de grupo, eles ficam perto uns dos outros, muitas vezes abraçados. Seus olhares convergem para a lente de modo que toda a imagem indique o seu centro ausente. Quando um casal é fotografado, seguram-se pela cintura numa pose inteiramente convencional. As normas de conduta frente à câmera às vezes se tornam conscientes, de uma forma positiva ou negativa. Por exemplo: um membro de um grupo reunido para uma ocasião solene, como um casamento, que adote uma postura relaxada, ou que deixe de olhar direto para a máquina ou fazer pose, é objeto de reprovação. Como é costume dizer, "ele não está realmente lá".

Fazer parte de uma fotografia é garantir o testemunho da presença, o que é a contrapartida obrigatória da homenagem recebida ao ter sido convidado; é expressar que se valoriza esta honra e que se está presente para retribuí-la ${ }^{16}$. Como poderia a disposição e a postura dos participantes deixar de ser marcadas pela solenidade? Ninguém pensa em infringir as instruções dadas pelo fotógrafo, falando com o vizinho ou olhando para outro lado. Isso seria uma indecência e, sobretudo, uma afronta ao grupo e, ainda mais, àqueles que são "homenageados naquele dia": os recém-casados. A posição correta e digna consiste em ficar de pé, direito, olhando em frente com a gravidade que convém a uma ocasião solene.

Não deixa de ser razoável admitir que a busca espontânea de frontalidade está ligada aos valores culturais mais enraizados ${ }^{17}$. Nesta sociedade que

\footnotetext{
16 "Se você assistir ao casamento de alguém e não estiver na fotografia, as pessoas vão reparar. 'Não estava no grupo', eles disseram que M. não estava na foto. Eles acham que você escapou, e isso cai mal" (J. L., dirigindo-se ao marido, durante uma entrevista).

17 Entre os cabílas, um homem de honra é aquele que dá a cara, que olha de cabeça erguida, que olha os outros na cara, mostrando a cara (BOURDIEU, 1965a).
} 
exalta o sentimento de honra, dignidade e responsabilidade; neste mundo fechado em que se sente a cada momento, e sem escapatória possível, os olhares constantes dos outros, é importante apresentar aos outros a imagem de si o mais honrosa possível: a postura fixa, rígida, que tem na "posição de sentido" dos soldados a expressão máxima, parece ser a expressão dessa intenção inconsciente. A imagem axial, em conformidade com o princípio de frontalidade, fornece uma impressão tão claramente legivel quanto possível, como se se quisesse evitar qualquer mal-entendido ou confusão. A mesma intenção se manifesta no embaraço sentido pelo sujeito fotografado, na preocupação de corrigir a postura e vestir as melhores roupas, na recusa instintiva em ser apanhado com as roupas do dia-a-dia, fazendo as coisas do cotidiano. Assumir a postura correta é uma forma de respeitar a si próprio e de exigir respeito. $\mathrm{O}$ personagem oferece ao espectador um ato de reverência, de cortesia, que é governado por convenções, e demanda que o espectador obedeça às mesmas convenções e às mesmas normas. Ele encara e pede para ser olhado frontalmente e à distância. Essa exigência de deferência recíproca constitui a essência da frontalidade. O retrato fotográfico leva a cabo, assim, a objetivação da imagem de si. Enquanto tal, ele é simplesmente o caso limite da relação com os outros ${ }^{18}$.

Tudo se passa como se, obedecendo ao princípio da frontalidade e adotando a postura mais convencional, se procurasse assumir tanto quanto possível o controle da objetivação da sua própria imagem. Olhar os outros sem ser visto; sem ser visto olhando e sem ser olhado; "roubar um olhar", como se diz, e, acima de tudo, fotografálos desta maneira é roubar a imagem dos outros. Ao olhar para a pessoa que olha para mim (ou que me fotografa), ao preparar a minha postura, doume para ser visto como quero ser visto; dou a imagem de mim próprio que quero dar e, muito simplesmente, dou a minha imagem. Em suma,

18 A fotografia é a situação na qual a consciência do próprio corpo perante os outros atinge a máxima acuidade. Cada um sente-se sob o olhar e sob um olhar que fixa e imobiliza as aparências. [Nota de Loïc Wacquant e Richard Nice: sobre os fundamentos sociais das dificuldades de relação com o corpo entre os camponeses e suas respectivas consequências estruturais, cf. BOURDIEU, 1962 e, neste número da] Revista de Sociologia e Política, o artigo O camponês e seu corpo. confrontado com um olhar que fixa e imobiliza aparências, adotar a mais digna das atitudes, a mais sóbria e a mais cerimonial, colocar-se de forma rígida e imóvel, com os pés juntos, os braços estendidos, como um soldado em sentido, é reduzir o risco de parecer desajeitado e inconveniente, é apresentar aos outros uma imagem controlada, preparada, aprimorada de si. Dar uma imagem controlada de si é uma forma de impor regras à própria percepção de si.

A convencionalidade da postura e da roupa adotada para as fotografias parece derivar do estilo das relações sociais promovidas por uma sociedade ao mesmo tempo hierárquica e estática, na qual a linhagem e a "casa" têm mais realidade do que os indivíduos particulares que a compõem, definidos essencialmente pelo grupo a que pertencem ${ }^{19}$; grupo em que as regras sociais de comportamento e o código moral estão mais presentes do que os sentimentos, as vontades ou os pensamentos dos indivíduos singulares, onde as trocas sociais, rigidamente reguladas por convenções consagradas, são cumpridas sob a ameaça do julgamento dos outros, sob o olhar de uma opinião coletiva pronta a condenar em nome de normas incontestáveis e incontestadas, e que são sempre dominadas pela preocupação em apresentar a melhor imagem de si, aquela que melhor se conforma com o ideal de dignidade e de honra ${ }^{20}$.

A solenização, o comportamento hierático e a eternização são inseparáveis. Na linguagem de todas as estéticas, a frontalidade exprime o eterno, por oposição ao profundo, através do qual a temporalidade é reintroduzida. Na pintura, o plano exprime ser ou essência; numa palavra, o intemporal (cf. BONNEFOY, 1959). Se uma ação é representada na pintura, ela é sempre um movimento essencial, "imóvel" e fora do tempo; é o equilíbrio ou o aplomb de um gesto eterno, tal como a norma ética ou social que incorpora: os

\footnotetext{
19 Não é raro para um filho mais novo que casa com uma filha mais velha e vai viver com os pais dela, perder o seu apelido, e, desse modo, ser designado apenas pelo nome da sua nova casa. [Nota de Loïc Wacquant e Richard Nice: as relações de parentesco e a reprodução da hierarquia de linhagem no Béarn são debatidas em profundidade em BOURDIEU, 1990, p. 147-161].

20 HAUSENSTEIN (1913, p. 759-760) elucida as ligações entre a visão frontal e a estrutura social de "sociedades feudais e hieráticas".
} 
esposos com os braços à volta um do outro exprimem, em outra postura, o mesmo significado que as mãos dadas dos bustos de Catão e Pórcia, no Vaticano.

A fotografia popular elimina o acidental ou o aspecto que, como imagem efêmera, dissolve o real temporalizando-o. O "instantâneo", a fotografia "tirada ao vivo" - que é uma expressão de uma visão do mundo nascido no Quattrocento, com a perspectiva - opera um corte instantâneo no mundo visível e, ao petrificar o gesto humano, imobiliza um estado único da relação recíproca entre as coisas, e prende o olhar num momento imperceptível de uma trajetória nunca completa. Já a fotografia em pose, que apenas agarra e fixa persona- gens instaladas, imóveis, na imutabilidade do plano, perde o seu poder de corrosão ${ }^{21}$. Desse modo, ao adotarem espontaneamente a organização e as posturas das figuras dos mosaicos de Bizâncio, os camponeses do Béarn que posam para uma fotografia de casamento parecem querer escapar ao poder que a fotografia tem para des-realizar o mundo temporalizando-o.

\footnotetext{
${ }^{21}$ Mais uma vez, abre-se uma exceção para as crianças, talvez porque mudar está na sua própria natureza: onde o objetivo é captar o efêmero e o acidental, a fotografia é apropriada, já que não pode captar o aspecto fugaz ao desaparecimento irreversível, sem o constituir como tal.
}

Pierre Bourdieu ocupou a cadeira de Sociologia no Collège de France, onde dirigiu também o Centro de Sociologia Européia e editou a revista Actes de la recherche en sciences sociales até sua morte em 2002. Ele é autor de vários livros clássicos em Sociologia e Antropologia, incluindo La Reproduction: éléments d'une théorie du système d'enseignement (com Jean-Claude Passeron; 1970), Esquisse d'une theorie de la pratique (1972), La Distinction: critique sociale du jugement (1979), Homo Academicus (1984) e Les règles de l'art: genèse et structure du champ littéraire (1992). Dentre seus estudos etnográficos estão: Le déracinement: la crise de l'agriculture traditionnelle en Algérie (com Adbelmalek Sayad, 1964), Algérie 60: structures économiques et structures temporelles (1977), La misère du monde (1993) e Le Bal des célibataires: crise de la societé em Béarn (2002).

Marie-Claire Bourdieu é historiadora de arte.

\section{REFERÊNCIAS BIBLIOGRÁFICAS}

BONNEFOY, Y. 1959. Le temps et l'intemporel dans la peinture du Quattrocento. In : L'Improbable et autres essais. Paris : Mercure de France.

BOURDIEU, P. 1962. Célibat et condition paysanne. Études rurales, n. 5-6, p. 32-136, avr.

. 1965a. The Sentiment of Honour in Kabyle Society. In : PERISTIANY, J. G. (ed.) Honour and Shame: The Values of Mediterranean Society. Londres : Weidenfeld and Nicolson.

.1965b. Un art moyen. Essais sur les usages sociaux de la photographie. Paris : Minuit

. 1990. The Logic of Practice. Cambridge : Cambridge University Press; Stanford : Stanford University Press.
2002. Le bal des célibataires. La crise de la société paysanne en Béarn. Paris : Points/ Seuil.

BOURDIEU, P. \& BOURDIEU, M.-C. 1965. Le paysan et la photographie. Revue française de sociologie, v. 6, n. 2, p. 164-174, avr.-juin.

2004. The peasant and photography. Ethnography, v. 5, n. 4, p. 601-616, Dec.

DURKHEIM, E. 1995 (1912). The Elementary Forms of Religious Life. New York : Free Press.

HAUSENSTEIN, W. 1913. Archiv für Sozialwissenschaft und Sozialpolitik, v. 36, Feb. 
THE PEASANT AND PHOTOGRAPHY

Pierre Bourdieu (Collège de France) and Marie-Claire Bourdieu

Drawing on an ethnography of the author's childhood village in southwestern France, this article analyses the social uses and meaning of photographs and photographic practice in the peasant society of Béarn in the early 1960s. Photography was first introduced on the occasion of the great ceremonies of familial and collective life, such as weddings, in which it fulfills the function of affirming the unity, standing, and boundaries of the lineages involved. Such ceremonies can be photographed because they lie outside the everyday routine and they must be photographed to solemnize and materialize the image that the group intends to present of itself. Thus photos are read and appreciated not in themselves and for themselves, in terms of their technical or aesthetic qualities, but as lay sociograms providing a visual record of extant social roles and relations.

KEYWORDS: photography; peasantry; technology; kinship; aesthetics; village culture; Béarn, France. 
LE PAYSAN ET LA PHOTOGRAPHIE

Pierre Bourdieu (Collège de France) et Marie-Claire Bourdieu

S'appuyant sur l'ethnographie du village du sud-ouest français où l'auteur a passé son enfance, cet article analyse les usages sociaux et le sens de la photographie et de la pratique photographique au sein de la société paysanne du Béarn, au début des années 1960. La photograhie y survient pour la première fois à l'occasion de céremonies importantes de la vie familiale et collective, comme les mariages, où elle jouait le rôle d'affirmer l'unité, la position et les frontières des lignées. Ces cérimonies pouvaient être photographiées parce qu'elles ne s'inséraient pas dans le quotidien, et devraient être photographiées pour célébrer et matérialiser l'image que le groupe voulait rendre de lui-même. Les photos ne sont donc pas vues et appréciées en tant que telles, c'est-à-dire par leurs qualités techniques ou esthétiques, mais comme des sociogrammes non professionnels qui permettent d'y inscrire visuellement les relations et les rôles sociaux.

MOTS-CLÉS : photographie; paysannat; technologie; parentèle; esthétique; culture locale; Béarn. 